\title{
Review
}

\section{Immune Responses to Neoadjuvant Chemotherapy in Muscle Invasive Bladder Cancer}

\author{
Amir Sherif ${ }^{\mathrm{a}, *}$, Malin Winerdal ${ }^{\mathrm{b}}$ and Ola Winqvist ${ }^{\mathrm{b}}$ \\ ${ }^{a}$ Department of Surgical and Perioperative Sciences, Urology and Andrology, Umeå University, Umeå, Sweden \\ ${ }^{\mathrm{b}}$ Department of Medicine, Immunology and Allergy Unit, Karolinska Institutet, Karolinska University Hospital, \\ Stockholm, Sweden
}

\begin{abstract}
The secondary effects of chemotherapy, with bone marrow depression and risk of leukopenia, has traditionally been considered being detrimental for the immune system. However, growing evidence suggests a main role for chemotherapy in antitumor immunomodulation. With reference to cisplatin, which is the basis of neoadjuvant chemotherapy in muscle invasive bladder cancer, four different aspects of immunomodulation has thus far been described; increased MHC class I expression, recruitment and proliferation of effector cells, enhancement of tumor-lytic activity of cytotoxic effectors and downregulation of immunosuppressive actors in the microenvironment. Consequently, the role of chemotherapy in cancer is changing from a therapy solely aimed at inducing tumor cell death, to a potent inducer of immune responses and a potential future major partaker in cancer immunotherapy. This is a great opportunity for the urological community to broaden research in this field in order to increase knowledge, optimize and improve the neoadjuvant regimens of muscle invasive bladder cancer to ultimately improve patient outcome.
\end{abstract}

Keywords: Urinary bladder neoplasms, cisplatin, neoadjuvant therapy, T-lymphocytes, B-lymphocytes, antigen-presenting cells

\section{ABBREVIATIONS}

APC

Adaptive immune system antigen presenting cell

leads to an immunological memory after an initial response to an antigen, leading to an enhanced response to repeated encounters with the specific antigen white blood cell of the lymphocyte subtype. Secrete antigen

\section{CTL}

DC

ICD

Innate immune system

MHC specific antibodies and also cytokines. Can act as APC

Cytotoxic T cell

Dendritic cells, functions as APCs immunogenic cell death the non-specific immune system as a first line primary defense which does not provide longlasting immunity major histocompatibility complex (displays peptide fragments of non-self proteins from within the tumor cell, for the immune system to interact with)

\footnotetext{
${ }^{*}$ Correspondence to: Dr. Amir Sherif, Department of Surgical and Perioperative Sciences, Urology and Andrology, Umeå University, 90185 Umeå, Sweden. Tel.: +46 705229104; Fax: +46 901253 96; E-mail: amir.m.sherif@gmail.com or amir.sherif@ urologi.umu.se.
} 


\begin{tabular}{|c|c|}
\hline MDSC & $\begin{array}{l}\text { myeloid-derived suppressor } \\
\text { cells which possess strong } \\
\text { immunosuppressive regulatory }\end{array}$ \\
\hline Tcell & $\begin{array}{l}\text { white blood cell of the lympho- } \\
\text { cyte subtype. Major player in the } \\
\text { cell-mediated immunity. Differ- } \\
\text { ent subsets with different } \\
\text { functions. }\end{array}$ \\
\hline TCR & $\mathrm{T}$ cell receptor \\
\hline T reg & $\begin{array}{l}\text { T regulatory cells, which are } \\
\text { considered to maintain strong } \\
\text { immunosuppressive regulatory } \\
\text { functions }\end{array}$ \\
\hline
\end{tabular}

\section{NEOADJUVANT CHEMOTHERAPY IN MUSCLE INVASIVE BLADDER CANCER}

The proposed rationale for neoadjuvant chemotherapy in muscle invasive urinary bladder cancer (MIBC), is the early treatment of undetected micro-metastatic disease prior to major surgery for maximum efficacy [1]. Neoadjuvant cisplatin based combination chemotherapy (NAC) has been proposed to be of value for downstaging of the primary tumor and facilitating surgical resection during radical cystectomy ( $\mathrm{RC}$ ), however, the overall survival benefit is only $5-8 \%$ in intention-to-treat settings [1-3]. In contrast, complete responders (pTONOM0) gain substantial survival benefits from NAC $[4,5]$, and the early identification of responders versus non-responders to NAC therapy is therefore an important area of research. Furthermore, retrospective evaluations of larger populations have revealed that NAC therapy is a positive prognostic factor also with regard to pTis, pTa and pT1 outcomes, similar to the findings in patients with pTONO [6]. Interestingly, a growing body of data suggests that NAC efficacy is not only due the induction of tumor cell death following the treatment, but also an anti-tumoral induction of the immune system. However, a solid connection between significant tumor downstaging and NAC-induced/enhanced immune responses, has yet to be demonstrated.

\section{TUMOR IMMUNOLOGY}

Mutations are at the center in the multistep process of cancer development, resulting in the formation of foreign proteins with the potential to be recognized by the immune system. The massive expansion of the tumor immunology field during the past decade, is illustrated by the update of the Hallmarks of Cancer theorem, to include tumor immune evasion as an emerging Hallmark [7]. Cancer immune surveillance [8] is the idea that the immune system continuously monitors and protects the body from developing cancer cells. In a proposed process called immunoediting, a malignancy undergoes three phases: (1) The elimination phase, during which immune surveillance prevails. (2) The equilibrium phase, where interactions between tumor cells and the immune system result in evolutionary pressure and "editing" of the tumor phenotype, and (3) the escape phase during which the tumor has acquired properties (i.e. escape mechanisms) allowing it to evade the immune system and grow $[8,9]$.

\section{Tumor escape mechanisms}

Tumor evasion of anti-tumor immune responses constitutes a challenge for future therapeutic strategies. Indeed, many of the latest drug introductions in cancer therapy directly target the natural breaks of the immune system, the most prominent examples being check-point inhibitors such as the monoclonal snitCTLA4 antibody ipilimumab and anti-PD1/PD-L1 therapies. A wide variety of tumor escape mechanisms have been described including altered antigen presentation, production of immunosuppressive factors and recruitment/induction of regulatory immune cell populations. Here follows a brief introduction to some of the most well studied tumor immune escape mechanisms.

\section{Downregulation of MHC class I}

MHC class I (MHCI) complexes present peptides from inside the cell on the cell surface enabling the recognition of altered antigens (so called neoantigens) by cytotoxic $\mathrm{T}$ cells (CTLs). Activation of CTLs triggers the release of effector substances such as granzyme and perforin, which in turn eliminate the tumor cells. To survive, many tumors down-regulate or alter their MHCI expression through a variety of different mechanisms such as deletion of the $\beta 2$ microglobulin genes, direct suppression of MHCI gene transcription or interference with the antigen presentation machinery such as the transporter associated with antigen processing (TAP) $[10,11]$.

\section{Induction of check point inhibitors}

Feedback loops are built into a normal immune response, in order to regulate the length and the mag- 


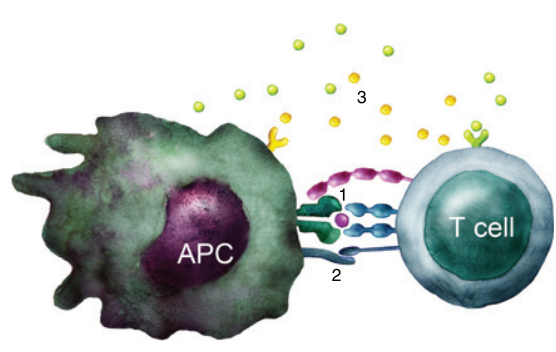

Fig. 1. T cell activation. Schematic illustration of the three signals required to activate a naïve T cell: 1) TCR stimulation by recognition of peptide-MHC complex. 2) Costimulation through e.g. CD28 interaction with B7 molecules such as CD80 and CD86. 3) Cytokines that influence the type of immune response developed.

nitude of immune activation. Once a naïve $\mathrm{T}$ cell recognizes a tumor derived peptide presented by an MHC molecule in a tumor draining lymph node, additional costimulatory signals such as CD80 and CD86 are needed for $\mathrm{T}$ cell activation (Fig. 1). During the progression of the immune response, activation is followed by upregulation of inhibitory receptors, such as CTLA-4 or PD-1 that compete with the T cell activation signals, leading to a diminished $\mathrm{T}$ cell response. Of note, tumors may induce and enhance the expression of CTLA-4, and PD-1/PD-L1, thus suppressing immune activation [12, 13]. The importance of these immune check points has been demonstrated during recent years by the development and clinical introduction of check point inhibitors such as ipilimumab and nivolumab, targeting these specific pathways $[14,15]$.

\section{The tumor microenvironment}

The tumor microenvironment is where the interactions between cancer cells and the immune system occur and it is very much connected to different modes of tumor immune escape. For example, tumors can actively express immune suppressive factors such as the enzyme indoleamine 2, 3-deoxygenase (IDO) [16], secrete immune modulating cytokines such as TGF- $\beta$ and IL-10 [11, 17], and moreover the relatively hypoxic environment within the tumor, can constitute an immunosuppressive factor in itself [18].

\section{CYTOTOXIC CHEMOTHERAPIES AND THE IMMUNE SYSTEM}

Cancer chemotherapy has traditionally been considered detrimental to the immune system, and had until recently not been evaluated in a broader context. Chemotherapy associated bone marrow depression with ensuing lymphopenia has been interpreted as a hallmark of a weakened immune system with ensuing risk for negative effects on long time survival. However, evidence suggests that lymphopenia may create prime conditions for restarting or re-booting large parts of the immune system through so called homeostasis-driven proliferation of immune cells (promoted by cytokines such as IL-7 and IL-15). The end effect being a diminished tolerance for the altered self-characteristics of tumor cells [19, 20].

\section{GENERAL ASPECTS ON CHEMOTHERAPY-INDUCED ANTITUMOR IMMUNOMODULATION}

\section{Chemotherapy and immunogenic cell death}

Interestingly, chemotherapeutic drugs have been shown to induce so called immunogenic cell death (ICD) in tumor cells, ultimately resulting in augmented immune responses in tumor vaccination experiments [21]. The tumor cell goes through different phases during the process of ICD, starting from the induced pre-apoptosis over apoptosis, to the final necrotic cell. In all three phases, the immune system interacts with damaged tumor cells in a concerted effort to eliminate the tumor. During the first phase, the DCs of the host, attempt to engulf the pre-apoptotic cell. This due to the tumor cell, after chemotherapy induced damage, starts to expose calreticulin (CRT) on the cell surface. CRT exposure seems to determine the engulfment of dying tumor cells by DCs, and can serve as an DC-activation signal [22]. In the apoptotic phase, the tumor cell releases ATP which attracts more DCs and further leads to a process of DC maturation. In the final necrotic phase, the cell membrane becomes more permeable, leading to release of HMBG-1, leading to further triggering of DCs and to enhanced T cell immunity activation $[23,24]$. Interestingly, different chemotherapeutic regimes appear to vary in their ability to induce ICD, suggesting that optimization of clinical chemotherapy protocols could lead to more ICD of tumor cells in patients and consequently better immune activation and clinical response to treatment [21].

\section{CISPLATIN IN THE CONTEXT OF IMMUNOMODULATION}

Since cisplatin is the main player in chemotherapy of MIBC, the following sections will focus on the 
immunomodulatory effects described for this drug in different settings. Of note, cisplatin as monotherapy in MIBC is considered less efficient than combination therapy, the latter being the Gold standard following the results of the randomized prospective trials $[2,3]$ and also in a major meta-analysis of all RCTs addressing the concept [25]. Apart from the listed immunomodulatory effects of cisplatin, other components in MVAC as well as in gemcitabine stand-alone, have also been shown to render antitumorous immunological effects [26, 27].

As of today, much work still remains to be done regarding the specific immunomodulatory effects of chemotherapy in MIBC.

\section{Basic immunomodulatory effects of cisplatin}

\section{Increased MHC class I expression}

Different research groups have demonstrated that cisplatin enhances cell expression of MHC I in experimental studies of tumor cell lines [28-31]. As discussed previously, MHC I is vital for tumor cell recognition and elimination by $\mathrm{CD}^{+}$cytotoxic $\mathrm{T}$ cells, and increased expression would thus accordingly promote anti-tumor immune responses.

\section{Recruitment and proliferation of effector cells}

Homing of effector cells to the actual target area (i.e. to the primary tumor or metastatic deposits) is of primary importance for an effective immune response to occur. Experimental investigations indicate cisplatin as a facilitator and promotor in the homing process [32, 33].

Interestingly, a combination of cisplatin and gemcitabine in a murine model, investigating mesothelioma and lung cancer tumors, led to substantially increased amounts of activated CTLs, both systematically and locally in the tumor [34].

\section{Enhancement of tumor-lytic activity of cytotoxic effectors}

Pretreatment of CTLs with cisplatin has been shown to increase CTL-mediated killing of tumor cells in lymphoblastoid cell lines [35]. Furthermore, it seems cisplatin can sensitize tumor cells to CTL-mediated killing as demonstrated in a colon carcinoma cell line, in which the mechanism was mediated through the upregulation of both ICAM-1 and Fas expression leading to an increase in caspase 3-like protease activity and apoptosis [36]. Moreover, in a study of human lung carcinoma cell lines with sublethal exposure to cisplatin/vinorelbine, the sensitivity to perforin/granzyme mediated CTLkilling was also significantly increased [37]. Another study of cisplatin in combination with adoptive $\mathrm{T}$ cell immunotherapy illustrated that cisplatin-treated tumor cells had increased perforin-independent permeability, leading to increased CTL-mediated Granzyme B activity, and subsequent lethal effects on the tumor cells [38].

\section{Downregulation of immunosuppressive actors in the microenvironment}

Cisplatin has been shown to downregulate both myeloid-derived suppressor cells (MDSC) and T regulatory cells (Treg) in separate studies, with postulated secondary effects on immunocompetent cells being unhampered in their respective activity [29, 32, 37]. Lesterhuis and associates have shown that exposure to platinum based chemotherapy markedly reduced PD-L2 expression (T cell inhibitory molecule programmed death receptor ligand 2), and the effect was determined both on DCs as well as tumor cells. The PD-L2 downregulation resulted in enhanced antigen-specific proliferation and Th1 cytokine secretion, which further improved recognition of tumor cells by $\mathrm{T}$ cells [39].

Experimental data indicates that cisplatin also has a function of displaying and presenting subdominant epitopes of tumor antigens. Thus, enhancing the possibility of the adaptive immune system (CTLs) to recognize otherwise hidden tumor targets. This is especially important due to the risk of immune evasion of an effective immune response towards the dominant epitope [40].

\section{CHEMOTHERAPY-INDUCED ANTI-TUMOR RESPONSES IN MIBC}

As mentioned previously, activation of $\mathrm{T}$ cells needs two signals, one provided by the MHCtumor peptide complex and one by costimulatory molecules such as B7.1 (CD80) and B7.2 (CD86). In addition, a third signal mediated by cytokines is responsible for optimal $\mathrm{T}$ cell activation. Our group previously demonstrated that cisplatin induces release of the T cell activating cytokine IFN- $\beta$ by APCs enhancing $T$ cell activation [41]. Recently we also demonstrated that doxorubicin treatment of $\mathrm{B}$ cells results in increased expression of the costimulatory molecule CD86 and increased T cell activation [42]. Blocking CD86 with a monoclonal antibody inhibited this $\mathrm{T}$ cell activation. In addi- 
tion, doxorubicin resulted in decreased production of the anti-inflammatory cytokine IL-10. To investigate the immunological response to doxorubicin, MIBC patients treated with NAC were investigated, demonstrating an increased expression of the costimulatory molecule CD86 of B cells. Thus, doxorubicin given as part of combination-NAC seems to support activation of $\mathrm{T}$ cells and anti-tumoral immune responses [42].

\section{FUTURE OPTIONS AND DIRECTIONS}

Although tumors can be defined by patient characteristics, histology and staging, this is not sufficient to fully understand an individual's treatment options, especially not with regards to upcoming immunotherapy approaches. It is important to account for the clinical and immune characteristics of the tumor as well as the patient's immunological status, not only on a group level, but ultimately for each individual patient. New evolving bladder cancer taxonomies from different research groups [43-45] need to be related to corresponding immunological properties, both in the different subgroups as well as in relation to both innate and adaptive immune responses.

The different compartments in which the tumor cells interact with the immunological defenses also warrant further investigation that includes, apart from the primary tumor, also blood, urine, bone marrow and tumor draining lymph nodes [46, 47].

The immunomodulatory effects of chemotherapy in bladder cancer that have been suggested during recent years, suggest that further research is needed to evaluate the best strategy for optimal administration of chemotherapy and its relative timing to the ensuing RC. A tailored approach would require individual optimization and we propose that there might be major advantages of monitoring each patient's immune responses regularly during the course of NAC-administration. Hypothetically, an inflexible general timetable with strictly predefined doses may otherwise lead to a suboptimal outcome in terms of endpoints related to immune induction, efficacy on micro-metastatic disease and even long term survival. The starting point should be immunological characterization already at time of primary diagnosis, preand post-TURb, in between NAC-cycles, pre- and post-RC and during follow up. Monitoring immunological status, developing and evaluating biomarkers of immunogenic cell death [48] opens up for individually adapted chemotherapy regimens to optimize the stimulatory effect of chemotherapy on the immune system.

\section{CONCLUSIONS}

Chemotherapy, once considered only an inductor of tumor cell death, can now be investigated, measured and utilized as possible tool for cancer immunotherapy. There are great opportunities for the scientific urological community to broaden the research in this field, in order to improve our knowledge and optimize neoadjuvant regimens in the field of muscle invasive bladder cancer.

\section{ACKNOWLEDGMENTS AND SOURCES OF SUPPORT}

This work was supported by the Swedish Cancer Society, the Wallenberg Foundation, the Swedish Medical Research Council, the Swedish Research Council funding for clinical research in medicine (ALF) in Västerbotten, VLL, Sweden, The Cancer Research Foundations of Radiumhemmet, and the Cancer Research Foundation in Norrland, Umeå, Sweden.

\section{CONFLICT OF INTEREST}

The authors have no conflicts of interest to report.

\section{REFERENCES}

[1] Witjes JA, Comperat E, Cowan NC, De Santis M, Gakis G, Lebret T, Ribal MJ, Van der Heijden AG, Sherif A. European Association of U. EAU guidelines on muscle-invasive and metastatic bladder cancer: Summary of the 2013 guidelines. European Urology 2014;65(4):778-92.

[2] Grossman HB, Natale RB, Tangen CM, Speights VO, Vogelzang NJ, Trump DL, deVere White RW, Sarosdy MF, Wood DP, Jr., Raghavan D, Crawford ED. Neoadjuvant chemotherapy plus cystectomy compared with cystectomy alone for locally advanced bladder cancer. The New England Journal of Medicine 2003;349(9):859-66.

[3] Sherif A, Holmberg L, Rintala E, Mestad O, Nilsson J, Nilsson S, Malmstrom PU, Nordic Urothelial Cancer G. Neoadjuvant cisplatinum based combination chemotherapy in patients with invasive bladder cancer: A combined analysis of two Nordic studies. European Urology 2004;45(3): 297-303.

[4] Rosenblatt R, Sherif A, Rintala E, Wahlqvist R, Ullen A, Nilsson S, Malmstrom PU, Nordic Urothelial Cancer G. Pathologic downstaging is a surrogate marker for efficacy 
and increased survival following neoadjuvant chemotherapy and radical cystectomy for muscle-invasive urothelial bladder cancer. European Urology 2012;61(6):1229-38.

[5] Lavery HJ, Stensland KD, Niegisch G, Albers P, Droller MJ. Pathological T0 following radical cystectomy with or without neoadjuvant chemotherapy: A useful surrogate. The Journal of Urology 2014;191(4):898-906.

[6] Zargar H, Zargar-Shoshtari K, Lotan Y, Shah JB, van Rhijn BW, Daneshmand S, Spiess PE, Black P, Collaborators. Final Pathological Stage after Neoadjuvant Chemotherapy and Radical Cystectomy for Bladder Cancer-Does pT0 Predict Better Survival than pTa/Tis/T1? The Journal of Urology 2016;195(4 Pt 1):886-93.

[7] Hanahan D, Weinberg RA. Hallmarks of cancer: The next generation. Cell 2011;144(5):646-74.

[8] Dunn GP, Old LJ, Schreiber RD. The three Es of cancer immunoediting. Annual Review of Immunology 2004;22: 329-60.

[9] Dunn GP, Old LJ, Schreiber RD. The immunobiology of cancer immunosurveillance and immunoediting. Immunity 2004;21(2):137-48.

[10] Hicklin DJ, Marincola FM, Ferrone S. HLA class I antigen downregulation in human cancers: T-cell immunotherapy revives an old story. Molecular Medicine Today 1999;5(4): 178-86.

[11] Rabinovich GA, Gabrilovich D, Sotomayor EM. Immunosuppressive strategies that are mediated by tumor cells. Annual Review of Immunology 2007;25:267-96.

[12] Contardi E, Palmisano GL, Tazzari PL, Martelli AM, Fala F, Fabbi M, Kato T, Lucarelli E, Donati D, Polito L, Bolognesi A, Ricci F, Salvi S, Gargaglione V, Mantero S, Alberghini M, Ferrara GB, Pistillo MP. CTLA-4 is constitutively expressed on tumor cells and can trigger apoptosis upon ligand interaction. International Journal of Cancer Journal International Du Cancer 2005;117(4):538-50.

[13] Blank C, Mackensen A. Contribution of the PD-L1/PD-1 pathway to T-cell exhaustion: An update on implications for chronic infections and tumor evasion. Cancer Immunology, Immunotherapy: CII 2007;56(5):739-45.

[14] Hodi FS, O'Day SJ, McDermott DF, Weber RW, Sosman JA, Haanen JB, Gonzalez R, Robert C, Schadendorf D, Hassel JC, Akerley W, van den Eertwegh AJ, Lutzky J, Lorigan P, Vaubel JM, Linette GP, Hogg D, Ottensmeier CH, Lebbe C, Peschel C, Quirt I, Clark JI, Wolchok JD, Weber JS, Tian J, Yellin MJ, Nichol GM, Hoos A, Urba WJ. Improved survival with ipilimumab in patients with metastatic melanoma. The New England Journal of Medicine 2010;363(8):711-23.

[15] Philips GK, Atkins M. Therapeutic uses of anti-PD1 and anti-PD-L1 antibodies. International Immunology 2015;27(1):39-46.

[16] Uyttenhove C, Pilotte L, Theate I, Stroobant V, Colau D, Parmentier N, Boon T, Van den Eynde BJ. Evidence for a tumoral immune resistance mechanism based on tryptophan degradation by indoleamine 2,3-dioxygenase. Nature Medicine 2003;9(10):1269-74.

[17] Wan YY, Flavell RA. 'Yin-Yang' functions of transforming growth factor-beta and $\mathrm{T}$ regulatory cells in immune regulation. Immunological Reviews 2007;220:199-213.

[18] Antonioli L, Blandizzi C, Pacher P, Hasko G. Immunity, inflammation and cancer: A leading role for adenosine. Nature Reviews Cancer 2013;13(12):842-57.

[19] Cho BK, Rao VP, Ge Q, Eisen HN, Chen J. Homeostasisstimulated proliferation drives naive $\mathrm{T}$ cells to differentiate directly into memory $\mathrm{T}$ cells. The Journal of Experimental Medicine 2000;192(4):549-56.
[20] Goldrath AW, Bogatzki LY, Bevan MJ. Naive T cells transiently acquire a memory-like phenotype during homeostasis-driven proliferation. The Journal of Experimental Medicine 2000;192(4):557-64.

[21] Galluzzi L, Buque A, Kepp O, Zitvogel L, Kroemer G Immunogenic cell death in cancer and infectious disease. Nature Reviews Immunology 2017;17(2):97-111.

[22] Zitvogel L, Kepp O, Senovilla L, Menger L, Chaput N, Kroemer G. Immunogenic tumor cell death for optimal anticancer therapy: The calreticulin exposure pathway. Clinical Cancer Research: An Official Journal of the American Association for Cancer Research 2010;16(12):3100-4.

[23] Apetoh L, Ghiringhelli F, Tesniere A, Criollo A, Ortiz C, Lidereau R, Mariette C, Chaput N, Mira JP, Delaloge S, Andre F, Tursz T, Kroemer G, Zitvogel L. The interaction between HMGB1 and TLR4 dictates the outcome of anticancer chemotherapy and radiotherapy. Immunological Reviews 2007;220:47-59.

[24] Apetoh L, Ghiringhelli F, Tesniere A, Obeid M, Ortiz C, Criollo A, Mignot G, Maiuri MC, Ullrich E, Saulnier P, Yang H, Amigorena S, Ryffel B, Barrat FJ, Saftig P, Levi F, Lidereau R, Nogues C, Mira JP, Chompret A, Joulin V, Clavel-Chapelon F, Bourhis J, Andre F, Delaloge S, Tursz T, Kroemer G, Zitvogel L. Toll-like receptor 4-dependent contribution of the immune system to anticancer chemotherapy and radiotherapy. Nature Medicine 2007;13(9):1050-9.

[25] Advanced Bladder Cancer Meta-analysis C. Neoadjuvant chemotherapy in invasive bladder cancer: Update of a systematic review and meta-analysis of individual patient data advanced bladder cancer (ABC) meta-analysis collaboration. European Urology 2005;48(2):202-5; discussion 5-6.

[26] Nowak AK, Robinson BW, Lake RA. Gemcitabine exerts a selective effect on the humoral immune response: Implications for combination chemo-immunotherapy. Cancer Research 2002;62(8):2353-8.

[27] Nowak AK, Lake RA, Marzo AL, Scott B, Heath WR, Collins EJ, Frelinger JA, Robinson BW. Induction of tumor cell apoptosis in vivo increases tumor antigen crosspresentation, cross-priming rather than cross-tolerizing host tumor-specific CD8 T cells. Journal of Immunology 2003; 170(10):4905-13

[28] Gelbard A, Garnett CT, Abrams SI, Patel V, Gutkind JS, Palena C, Tsang KY, Schlom J, Hodge JW. Combination chemotherapy and radiation of human squamous cell carcinoma of the head and neck augments CTL-mediated lysis. Clinical Cancer Research: An Official Journal of the American Association for Cancer Research 2006;12(6): 1897-905.

[29] Tseng CW, Hung CF, Alvarez RD, Trimble C, Huh WK, Kim D, Chuang CM, Lin CT, Tsai YC, He L, Monie A, Wu TC. Pretreatment with cisplatin enhances E7-specific CD8+T-Cell-mediated antitumor immunity induced by DNA vaccination. Clinical Cancer Research: An Official Journal of the American Association for Cancer Research 2008;14(10):3185-92.

[30] Nio Y, Hirahara N, Minari Y, Iguchi C, Yamasawa K, Toga T, Tamura K. Induction of tumor-specific antitumor immunity after chemotherapy with cisplatin in mice bearing MOPC$104 \mathrm{E}$ plasmacytoma by modulation of MHC expression on tumor surface. Anticancer Research 2000;20(5A):3293-9.

[31] Ohtsukasa S, Okabe S, Yamashita H, Iwai T, Sugihara K. Increased expression of CEA and MHC class I in colorectal cancer cell lines exposed to chemotherapy drugs. Journal of Cancer Research and Clinical Oncology 2003;129(12): 719-26. 
[32] Chang CL, Hsu YT, Wu CC, Lai YZ, Wang C, Yang YC, Wu TC, Hung CF. Dose-dense chemotherapy improves mechanisms of antitumor immune response. Cancer Research 2013;73(1):119-27.

[33] Chen J, Huang X, Huang G, Chen Y, Chen L, Song $\mathrm{H}$. Preconditioning chemotherapy with cisplatin enhances the antitumor activity of cytokine-induced killer cells in a murine melanoma model. Cancer Biother Radiopharm 2012;27(3):210-20.

[34] Fridlender ZG, Sun J, Singhal S, Kapoor V, Cheng G, Suzuki E, Albelda SM. Chemotherapy delivered after viral immunogene therapy augments antitumor efficacy via multiple immune-mediated mechanisms. Molecular Therapy: The Journal of the American Society of Gene Therapy 2010;18(11):1947-59.

[35] Markasz L, Skribek H, Uhlin M, Otvos R, Flaberg E, Eksborg S, Olah E, Stuber G, Szekely L. Effect of frequently used chemotherapeutic drugs on cytotoxic activity of human cytotoxic T-lymphocytes. Journal of Immunotherapy 2008;31(3):283-93.

[36] Bergmann-Leitner ES, Abrams SI. Treatment of human colon carcinoma cell lines with anti-neoplastic agents enhances their lytic sensitivity to antigen-specific CD8+ cytotoxic T lymphocytes. Cancer Immunology, Immunotherapy: CII 2001;50(9):445-55.

[37] Gameiro SR, Caballero JA, Higgins JP, Apelian D, Hodge JW. Exploitation of differential homeostatic proliferation of T-cell subsets following chemotherapy to enhance the efficacy of vaccine-mediated antitumor responses. Cancer Immunology, Immunotherapy: CII 2011;60(9):1227-42.

[38] Ramakrishnan R, Assudani D, Nagaraj S, Hunter T, Cho HI, Antonia S, Altiok S, Celis E, Gabrilovich DI. Chemotherapy enhances tumor cell susceptibility to CTL-mediated killing during cancer immunotherapy in mice. The Journal of Clinical Investigation 2010;120(4):1111-24.

[39] Lesterhuis WJ, Punt CJ, Hato SV, Eleveld-Trancikova D, Jansen BJ, Nierkens S, Schreibelt G, de Boer A, Van Herpen CM, Kaanders JH, van Krieken JH, Adema GJ, Figdor CG, de Vries IJ. Platinum-based drugs disrupt STAT6mediated suppression of immune responses against cancer in humans and mice. The Journal of Clinical Investigation 2011;121(8):3100-8.

[40] Jackaman C, Majewski D, Fox SA, Nowak AK, Nelson DJ. Chemotherapy broadens the range of tumor antigens seen by cytotoxic CD8(+) T cells in vivo. Cancer Immunology, Immunotherapy: CII 2012;61(12):2343-56.
[41] Hu J, Kinn J, Zirakzadeh AA, Sherif A, Norstedt G, Wikstrom AC, Winquist O. The effects of chemotherapeutic drugs on human monocyte-derived dendritic cell differentiation and antigen presentation. Clinical and Experimental Immunology 2013;172(3):490-9.

[42] Zirakzadeh AA, Kinn J, Krantz D, Rosenblatt R, Winerdal ME, Hu J, Hartana CA, Lundgren C, Bergman EA, Johansson M, Holmstrom B, Hansson J, Sidikii A, Vasko J, Marits P, Sherif A, Winqvist O. Doxorubicin enhances the capacity of B cells to activate T cells in urothelial urinary bladder cancer. Clinical Immunology 2017;176:63-70.

[43] Sjodahl G, Lovgren K, Lauss M, Patschan O, Gudjonsson S, Chebil G, Aine M, Eriksson P, Mansson W, Lindgren D, Ferno M, Liedberg F, Hoglund M. Toward a molecular pathologic classification of urothelial carcinoma. Am J Pathol 2013;183(3):681-91.

[44] Volkmer JP, Sahoo D, Chin RK, Ho PL, Tang C, Kurtova AV, Willingham SB, Pazhanisamy SK, Contreras-Trujillo H, Storm TA, Lotan Y, Beck AH, Chung BI, Alizadeh AA, Godoy G, Lerner SP, van de Rijn M, Shortliffe LD, Weissman IL, Chan KS. Three differentiation states riskstratify bladder cancer into distinct subtypes. Proceedings of the National Academy of Sciences of the United States of America 2012;109(6):2078-83.

[45] Choi W, Porten S, Kim S, Willis D, Plimack ER, HoffmanCensits J, Roth B, Cheng T, Tran M, Lee IL, Melquist J, Bondaruk J, Majewski T, Zhang S, Pretzsch S, Baggerly K, Siefker-Radtke A, Czerniak B, Dinney CP, McConkey DJ. Identification of distinct basal and luminal subtypes of muscle-invasive bladder cancer with different sensitivities to frontline chemotherapy. Cancer Cell 2014;25(2):152-65.

[46] Marits P, Karlsson M, Sherif A, Garske U, Thorn M, Winqvist O. Detection of immune responses against urinary bladder cancer in sentinel lymph nodes. European Urology 2006;49(1):59-70.

[47] Pretscher D, Distel LV, Grabenbauer GG, Wittlinger M, Buettner M, Niedobitek G. Distribution of immune cells in head and neck cancer: CD8+T-cells and CD20+B-cells in metastatic lymph nodes are associated with favourable outcome in patients with oro- and hypopharyngeal carcinoma. BMC Cancer 2009;9:292.

[48] Ladoire S, Enot D, Andre F, Zitvogel L, Kroemer G. Immunogenic cell death-related biomarkers: Impact on the survival of breast cancer patients after adjuvant chemotherapy. Oncoimmunology 2016;5(2):e1082706. 